\title{
EFFECT OF ECCENTRIC CYCLING AND PLYOMETRIC TRAINING ON PHYSIOLOGICAL AND PERFORMANCE RELATED PARAMETERS OF TRAINED JUNIOR TRACK CYCLISTS
}

\author{
SUROJIT SARKAR ${ }^{1}$ SUVAM DASGUPTA², K. KOSANA MEITEI ${ }^{3}$, SNEHUNSU ADHIKARI $^{4}$, AMIT $^{2}$ \\ BANDYOPADHYAY ${ }^{5}$, SWAPAN KUMAR DEY6
}

\author{
ISenior Research Fellow (Physiology), Sports Authority of India, N.S.E.C., Kolkata, India \\ 2Senior Research Fellow (Biochemistry), Sports Authority of India, N.E.R.C., Imphal, India \\ 3In-charge (SS E FC), Sports authority of India, N.E.R.C., Imphal, India \\ ${ }^{4} J S O$ (Physiology), Sports Authority of India, N.S.E.C., Kolkata, India \\ ${ }^{5}$ Assistant professor, Sports and Exercise Physiology Laboratory, Department of Physiology, \\ University College of Science and Technology, University of Calcutta, India \\ ${ }^{6}$ Consultant Scientist, Sports Authority of India, N.S.E.C., Kolkata, India
}

Mailing address: Swapan Kumar Dey, Sports Authority of India, N.S.E.C., Kolkata 700106, India, tel.: +91 9433188340, e-mail: drskdey.sai@gmail.com

\begin{abstract}
Introduction. Some certain well-established training protocols exist for developing physical and physiological demands of a track cyclist. But still there is controversy on the effectiveness of combined training protocols. The present study was aimed to investigate the effects of 4-week concurrent eccentric cycling and plyometric training on cycling performance of male cyclists at the pre-competitive phase. Material and methods. A paired study design was applied to 15 young (15.04 $\pm 1.01 \mathrm{yrs})$ Indian male track cyclists to assess the effects of proposed concurrent training protocol on body composition and various physical fitness parameters. Results. Hydration status [TBW $(\sim 1 \%)$ and ICW $(\sim 1 \%)$, glycogen content $(\sim 3 \%)$, muscular strength $(\sim 6-11 \%)$, trunk flexibility $(\sim 5 \%)$, anaerobic power output ( $\sim 9 \%)$, endurance capacity $(\sim 5 \%)$, acceleration $(\sim 7 \%)$, leg explosive strength $(\sim 7 \%)$ and agility $(\sim 2 \%)$ were found to be improved significantly after the 4-week concurrent training protocol. Conclusions. The concurrent intervening physical training protocol was intended to increase muscular hypertrophy, peripheral factor gradient, glycolytic and oxidative enzyme capacity with proper neuromuscular coordination which may ultimately help the cyclists to pedal at a faster rate with higher muscular power output even for longer time.
\end{abstract}

Key words: concurrent training, muscular strength, anaerobic power output, $\mathrm{VO}_{2 \max }$

\section{Introduction}

Sports training refers to specialized strategies and methods which aim to optimize an athlete's performance. To be a successful track cyclist, sprinting ability, explosive leg strength and anaerobic power should be improved in a proper direction [1]. Body composition is one of the major factors which can limit the competitive cycling performance, as confirmed by Ebert et al., who claimed that acceleration is inversely proportional to weight [2]. By increasing the functional lean muscle to nonfunctional mass ratio, the power output can be optimized in relative terms by manipulating body weight, which has the potential to improve cycling performance [3].

Eccentric cycling (ECC) is a common training method intended to generate higher pedaling force for improving the performance with individually adapted and gradually increased training intensity, in which a muscle undergoes forced lengthening while bearing an external load and exerts braking actions causing an overload of the muscular system with a lower metabolic demand (lower $\mathrm{VO}_{2}$ ) [4, 5]. ECC also enables an individual to perform high loads on the musculoskeletal system with minimal stress on the cardiovascular system and with a low energy cost [4]. Eccentric exercise induces delayed onset muscle soreness, muscle fiber disruption and functional impairment, as shown by the concomitant decrease in maximal voluntary contraction (MVC) and maximal power output [6]. Reeves et al. revealed that adults had higher strength gains after eccentric strength training than after conventional concentric and isometric muscle actions [7]. At similar mechanical power output, ECC cycling elicits lower oxygen consumption $\left(\mathrm{VO}_{2}\right)[8,9]$ and reduced ventilator [10] and cardio-circulatory responses [11]. Studies like Moysi et al. [12] and Vogt M. and Hoppeler [13] tried to establish the positive effect of ECC on improving cycling performance but, on the other hand, research such as Paulsen et al. [14] encouraged the controversy over the resultant effectiveness of ECC.

Plyometric training (PLYO) intended to increase the subsequent movement power by using the elastic components of tendon, muscle and stretch reflex which can ultimately lead to improve the muscular movement, speed and power [15]. It also reduces the required timing for voluntary muscle contraction resulting in improved agility and emphasizes stretch-shortening cycle that involves both closed and open kinetic chain exercises even over a short period of time ( $<10$ weeks) [16]. PLYO has an impact on improved muscular performance and it is believed to be capable of bringing about alteration in muscle 
activation, neural activation and faster force generation [17]. PLYO improves power through increased neural drive, changes in muscle coordination, changes in the muscle tendon complex and changes in muscle size and architecture [17]. Plyometrics also showed to increase the cross-sectional areas of both type I and type II muscle fibers [18] without any change to the myosin heavy chain ratios [19]. Increased muscle preparatory activity and muscle activation were also found, leading to plyometrics possibly even preventing injury [17].

Studies reported the effects of either eccentric cycling [12, 13] or plyometric training [16] on cyclists separately. However, no studies were found which could clarify the effectiveness of combined eccentric and plyometric training protocol, and the pre-competitive efficacy of the combined training was still unclear. Moreover, there are still controversies whether the repeated bouts of eccentric and plyometric training can lead to functional impairment for the performance gain or not. Therefore, the present study was aimed to investigate the effects of 4-week concurrent eccentric cycling and plyometric training on cycling performance at the pre-competitive phase. The study was further aimed not only to eradicate the conflict regarding the effects of ECC on the performance of cyclists but also to establish the relationship between physical fitness parameters and different components of body composition profile.

\section{Material and methods}

\section{Subjects}

The present study was conducted on junior Indian male track cyclists $(n=15)$. The training protocol was implemented at the beginning of the pre-competitive phase. Cyclists were divided into two groups, i.e., before intervention $(\mathrm{n}=15)$ and after intervention $(n=15)$. All the subjects had a minimum of 4 years of professional experience as cyclists in at least state level competitions. They demonstrated similar socio-economic status and dietary habits and got trained in similar environmental/ climatic conditions, which made them homologous in nature. Athletes were clinically examined before commencement of the test and only the medically fit ones were chosen as subjects for the present study. A written informed consent was obtained from each subject and the study protocol conforms to the ethical guidelines of the Declaration of Helsinki, 1975. Institutional ethical clearance was also obtained prior to the beginning of the study.

\section{Sample size calculation}

Sample size was calculated by using PS Power and Sample Size Calculation version 2.1.30, where type-I error probability was 0.05 and power was 0.8 . The difference in population means was 2.7 and the standard deviation of differences in the response of matched pairs was 0.9. Therefore, the calculated sample size was 4 subjects only. However, considering a maximum of $50 \%$ dropout, 6 subjects needed to be recruited. However, to be safe-sided, 15 subjects were recruited in the present investigation [20].

\section{Combined training protocol}

The formulation and implementation of concurrent repeated ECC and PLYO protocol was done by the qualified coaches of Sports Authority of India under the supervision of scientific experts. All fifteen track cyclists went through a set of body composition and physical fitness assessments before and after completing the 4-week intensified training.

ECC training for $1 \mathrm{hr}$ and PLYO training for 30 mins were commonly given in both the morning and evening session, where the morning session consisted of PLYO (set-1) and the evening session took PLYO (set-2). Each training session began with a 10 min warm-up of stretching, bending and slow running and ended up with a brief cool down session. After every set, 2 min complete rest was given to the subjects.

ECC Protocol: Subjects performed the ECC protocol on a bicycle ergometer (Ergoline, VIA sprint 150P, Germany) and the heart rate was monitored by Polar heart rate monitor (Polar RS800CX, Polar Electro OY, Kempele, Finland). After adjusting the seat height, every cyclist was asked to pedal without any load for the first 2 mins for familiarization with the bicycle. Then they were instructed to pedal at the speed of $40 \mathrm{rpm}$ for the given time frame. Training intensity was applied according to the age-predicted HRmax (varying from $76 \%$ to $95 \%$ HRmax) in both training sessions (details given in Table 1). Participants were reported to the laboratory 30 mins prior to the test and the ambient temperature was maintained at $20^{\circ} \mathrm{C}$ with relative humidity of $50-60 \%$.

The Borg Category-Ratio scale (CR10 scale) which is considered both valid and reliable at measuring perceived exertion or pain was used to fix the target intensity. The participants were asked to perform ECC at an intensity starting at 4 (moderate to strong) in the first sessions, and increasing to 7 (very strong) in the last sessions [21].

Table 2. Details of 4-week plyometric (PLYO) training protocol

\begin{tabular}{|c|c|c|c|c|c|}
\hline Week & PLYO sets & Week 1 & Week 2 & Week 3 & Week 4 \\
\hline $\begin{array}{c}\text { SET-1 } \\
\text { (morning session) }\end{array}$ & $\begin{array}{l}\text { Single leg push-off } \\
\text { Box jump } \\
\text { Depth jump } \\
\text { Squat jump } \\
\text { Wave squat } \\
\text { Multiple box-to-box jumps } \\
\text { Foot contracts }\end{array}$ & $\begin{array}{l}3 \text { sets } \times 8 \text { rep. } \\
3 \text { sets } \times 5 \text { rep. } \\
3 \text { sets } \times 5 \text { rep. } \\
3 \text { sets } \times 12 \text { rep. } \\
3 \text { sets } \times 5 \text { rep. } \\
5 \text { times } \\
100 \text { times }\end{array}$ & $\begin{array}{l}3 \text { sets } \times 9 \text { rep. } \\
3 \text { sets } \times 6 \text { rep. } \\
3 \text { sets } \times 6 \text { rep. } \\
3 \text { sets } \times 12 \text { rep. } \\
3 \text { sets } \times 5 \text { rep. } \\
5 \text { times } \\
115 \text { times }\end{array}$ & $\begin{array}{l}3 \text { sets } \times 10 \text { rep. } \\
3 \text { sets } \times 6 \text { rep. } \\
3 \text { sets } \times 6 \text { rep. } \\
3 \text { sets } \times 12 \text { rep. } \\
3 \text { sets } \times 5 \text { rep. } \\
6 \text { times } \\
130 \text { times }\end{array}$ & $\begin{array}{l}3 \text { sets } \times 10 \text { rep. } \\
3 \text { sets } \times 7 \text { rep. } \\
3 \text { sets } \times 7 \text { rep. } \\
3 \text { sets } \times 12 \text { rep. } \\
3 \text { sets } \times 5 \text { rep. } \\
6 \text { times } \\
140 \text { times }\end{array}$ \\
\hline $\begin{array}{c}\text { SET-2 } \\
\text { (evening session) }\end{array}$ & $\begin{array}{l}\text { Standing jump over barrier } \\
\text { Lateral jump over barrier } \\
\text { Double leg hops } \\
\text { 5-5-5 squat } \\
\text { Front cone hops } \\
\text { Box jump } \\
\text { Foot contracts }\end{array}$ & $\begin{array}{l}3 \text { sets } \times 5 \text { rep. } \\
3 \text { sets } \times 5 \text { rep. } \\
3 \text { times } \\
3 \text { times } \\
4 \text { cones } \times 5 \text { times } \\
3 \text { sets } \times 5 \text { rep. } \\
100 \text { times }\end{array}$ & $\begin{array}{l}4 \text { sets } \times 5 \text { rep. } \\
4 \text { sets } \times 5 \text { rep. } \\
3 \text { times } \\
3 \text { times } \\
4 \text { cones } \times 5 \text { times } \\
4 \text { sets } \times 5 \text { rep. } \\
115 \text { times }\end{array}$ & $\begin{array}{l}4 \text { sets } \times 6 \text { rep. } \\
4 \text { sets } \times 6 \text { rep. } \\
3 \text { times } \\
4 \text { times } \\
4 \text { cones } \times 5 \text { times } \\
4 \text { sets } \times 5 \text { rep. } \\
130 \text { times }\end{array}$ & $\begin{array}{l}4 \text { sets } \times 6 \text { rep. } \\
4 \text { sets } \times 6 \text { rep. } \\
3 \text { times } \\
4 \text { times } \\
4 \text { cones } \times 5 \text { times } \\
4 \text { sets } \times 5 \text { rep. } \\
140 \text { times }\end{array}$ \\
\hline
\end{tabular}


Table 1. Details of 4-week eccentric cycling (ECC) training protocol

\begin{tabular}{|c|c|c|c|c|}
\hline \multirow{2}{*}{ Week } & \multirow{2}{*}{ ECC } & \multirow{2}{*}{$\begin{array}{l}\text { Borgs } \\
\text { CR10 }\end{array}$} & \multicolumn{2}{|c|}{ Aerobic interval } \\
\hline & & & (1st session) & (2nd session) \\
\hline 1 & $5 \times 2 \mathrm{~min}$ & 4 & $\begin{array}{c}4 \times 12 \min \\
(76-80 \% \text { HRmax })\end{array}$ & $\begin{array}{c}4 \times 15 \min \\
(76-80 \% \text { HRmax })\end{array}$ \\
\hline 2 & $6 \times 2 \min$ & 5 & $\begin{array}{c}4 \times 12 \min \\
(81-85 \% \text { HRmax })\end{array}$ & $\begin{array}{c}4 \times 15 \min \\
(81-85 \% \text { HRmax })\end{array}$ \\
\hline 3 & $7 \times 2 \min$ & 6 & $\begin{array}{c}4 \times 12 \min \\
(86-90 \% \text { HRmax })\end{array}$ & $\begin{array}{c}4 \times 15 \text { min } \\
(86-90 \% \text { HRmax })\end{array}$ \\
\hline 4 & $8 \times 2 \mathrm{~min}$ & 7 & $\begin{array}{c}4 \times 12 \min \\
(91-95 \% \text { HRmax })\end{array}$ & $\begin{array}{c}4 \times 15 \text { min } \\
(91-95 \% \text { HRmax })\end{array}$ \\
\hline
\end{tabular}

PLYO Protocol: The PLYO protocol was employed daily for six days a week for 4 weeks (details given in Table 2). Two different sets of PLYO exercises for lower limbs were done in morning and evening sessions and the intensity of training was gradually increased every week. Every PLYO session consisted of (4 sets $\mathrm{x}$ 6 repetitions) backward throw, overhead throw and trunk rotation together for balanced musculature and strength development.

\section{Anthropometric measurement}

Standing height $(\mathrm{cm})$ was measured to the nearest $0.1 \mathrm{~cm}$ using a digital Seca Alpha stadiometer, and body weight $(\mathrm{kg})$ was measured to the nearest $0.1 \mathrm{~kg}$ with the use of the calibrated digital Seca Alpha weighing scale (model 770) [22]. Handgrip strength $(\mathrm{kg})$, relative back strength and trunk flexibility $(\mathrm{cm})$ were measured with the help of the digital handgrip dynamometer, back strength dynamometer and sit-reach box (flexometer), respectively [23].

\section{Estimation of body composition}

Body composition was analyzed by using Multi-Frequency Bioelectrical Impedance Analyzer (MF-BIA). Basal metabolic rate (BMR), total body water (TBW), extracellular water $(\mathrm{ECW})$, intracellular water (ICW), total body potassium (TBK), total body calcium (TBCa), minerals and glycogen content were assessed through the analyzer by using four different frequencies $(5,50,100$ and $200 \mathrm{KHz})$ against an alternate current of $0.2 \mathrm{~mA}$ to create the total body electrical impedance, and the measurements were recorded following the standard testing manual of Maltron International (Maltron Bioscan 920 - II operating system and service manual) [24].

\section{Measurement of maximal aerobic capacity $\left(\mathrm{VO}_{2 \max }\right)$}

$\mathrm{VO}_{2 \max }$ was predicted using the modified $20 \mathrm{~m}$ multistage shuttle run test (or Beep test) [24]. Athletes had to maintain the running speed over the $20 \mathrm{~m}$ distance with the increasing frequency of 'beep' sound. The final estimation of $\mathrm{VO}_{2 \max }$ was obtained from the shuttle scores by using a standard chart of Beep test.

\section{Determination of anaerobic power}

Running based Anaerobic Sprint Test (RAST) was done to measure power output of the athletes [24]. Six consecutive sprints were done with maximum acceleration and $10 \mathrm{sec}$ interval after each sprint. Each sprint time was recorded with the use of the Brower timing gate system (Brower Timing Systems, USA).

\section{Determination of motor ability variables}

Measurement of motor ability variables was accomplished via testing $6 \times 10 \mathrm{~m}$ shuttle run, $30 \mathrm{~m}$ flying start and vertical jump to assess agility, acceleration and explosive leg strength, respectively. In $6 \times 10 \mathrm{~m}$ shuttle run, athletes sprinted as fast as possible to reach the opposite lines marked $10 \mathrm{~m}$ apart from both directions. Timing was started with the beginning of the $1^{\text {st }}$ shuttle and stopped when the athlete's torso crossed the line on returning from the $6^{\text {th }}$ sprint. Sprinting time was recorded by using a stopwatch [25].

In $30 \mathrm{~m}$ flying start, two cones were placed $30 \mathrm{~m}$ apart and another cone was placed $15 \mathrm{~m}$ away from the starting cone. This extra $15 \mathrm{~m}$ distance enabled the athletes to accelerate so that they could cover the actual $30 \mathrm{~m}$ distance at their maximum speed [26]. Each sprinting time was recorded by using the Brower timing gate system (Brower Timing Systems, USA).

In the vertical jump (VJ) test, athletes were asked to stand side to a wall by keeping feet remaining on the ground, reach up as high as possible with one hand and mark the wall with the tip of the finger (M1). From a static position, the athlete jumped as high as possible and marked the wall with chalk on his finger (M2). The distance between M1 and M2 was measured to the nearest $0.1 \mathrm{~cm}[26]$.

\section{Measurement of hemoglobin level}

Blood samples were obtained from the antecubital vein under random conditions. Immediately after blood collection, hemoglobin $(\mathrm{Hb})$ measurement was performed following the standard procedure of Bozkaya et al. [27] by using a Beckman Coulter Gen S automated hematology analyzer (Beckman Coulter Inc., Fullerton, CA, USA).

\section{Statistical Analysis}

Statistical analysis was done by with the use of the Statistical Program for the Social Sciences (SPSS) version 16.0 for Windows (SPSS Inc., Chicago, Il, USA). All values were expressed as means \pm standard deviation (SD). The assumption of normality was verified using the Shapiro-Wilk W-test. Differences between means of pre- and post-training groups for all variables were determined using paired sample t-test with two-tailed significance at $95 \%$ confidence interval.

Table 3. Comparison of general anthropometric parameters between pre- and post-training groups of male cyclists

\begin{tabular}{|l|c|c|c|c|c|}
\hline \multicolumn{1}{|c|}{ Parameters } & Before intervention $(\mathbf{n = 1 5 )}$ & After intervention $(\mathbf{n = 1 5 )}$ & Level of sig. & $\mathbf{t}$ value & \% change \\
\hline Age $(\mathrm{yrs})$ & $15.04 \pm 1.01$ & $15.27 \pm 0.73$ & $0.102(\mathrm{NS})$ & 1.750 & $(\uparrow) 1.53$ \\
\hline Body height $(\mathrm{kg})$ & $166.85 \pm 6.19$ & $167.20 \pm 5.52$ & $0.207(\mathrm{NS})$ & 1.322 & $(\uparrow) 0.21$ \\
\hline Body weight $(\mathrm{cm})$ & $57.93 \pm 4.45$ & $57.90 \pm 4.34$ & $0.902(\mathrm{NS})$ & 0.126 & $(\downarrow) 0.05$ \\
\hline BMR & $1787.73 \pm 101.30$ & $1788.13 \pm 99.04$ & $0.898(\mathrm{NS})$ & 0.131 & $(\uparrow) 0.02$ \\
\hline
\end{tabular}

Values are expressed as (mean $\pm \mathrm{SD})$, NS $=$ not significant. 
Table 4. Comparison of body composition indices between pre- and post-training groups of male cyclists

\begin{tabular}{|c|c|c|c|c|c|}
\hline Parameters & Before intervention $(n=15)$ & After intervention ( $n=15)$ & Level of sig. & t value & $\%$ change \\
\hline FFM \% & $83.27 \pm 4.45$ & $84.50 \pm 4.88$ & $0.118(\mathrm{NS})$ & 1.667 & $(\uparrow) 1.48$ \\
\hline Fat $\%$ & $16.73 \pm 4.45$ & $15.50 \pm 4.88$ & $0.118(\mathrm{NS})$ & 1.667 & $(\downarrow) 7.35$ \\
\hline TBW (\%) & $59.72 \pm 3.00$ & $60.55 \pm 2.80$ & $0.001^{* * *}$ & 4.319 & $(\uparrow) 1.39$ \\
\hline TBW/kg body weight & $1.04 \pm 0.11$ & $1.05 \pm 0.10$ & $0.019^{* *}$ & 2.641 & $(\uparrow) 0.96$ \\
\hline TBW/FFM & $0.72 \pm 0.03$ & $0.72 \pm 0.03$ & $0.995(\mathrm{NS})$ & 0.007 & - \\
\hline ECW (\%) & $35.40 \pm 2.54$ & $34.66 \pm 2.30$ & $0.007^{* *}$ & 3.140 & $(\downarrow) 2.09$ \\
\hline ECW/kg body weight & $0.61 \pm 0.06$ & $0.60 \pm 0.06$ & $0.037^{*}$ & 2.307 & $(\downarrow) 1.64$ \\
\hline ECW/FFM & $0.43 \pm 0.03$ & $0.41 \pm 0.03$ & $0.005^{* *}$ & 3.319 & $(\downarrow) 4.65$ \\
\hline $\operatorname{ICW}(\%)$ & $64.60 \pm 2.54$ & $65.34 \pm 2.30$ & $0.007^{* *}$ & 3.140 & $(\uparrow) 1.15$ \\
\hline ICW/kg body weight & $1.12 \pm 0.12$ & $1.14 \pm 0.10$ & $0.094(\mathrm{NS})$ & 1.794 & $(\uparrow) 1.78$ \\
\hline ICW/FFM & $0.78 \pm 0.06$ & $0.78 \pm 0.06$ & 0.781 (NS) & 0.284 & - \\
\hline ECW/ICW & $0.55 \pm 0.06$ & $0.53 \pm 0.06$ & $0.008^{* *}$ & 3.121 & 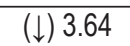 \\
\hline TBK (gm) & $123.73 \pm 11.15$ & $124.03 \pm 10.69$ & 0.363 (NS) & 0.941 & $(\uparrow) 0.24$ \\
\hline TBCa (gm) & $863.93 \pm 142.33$ & $880.00 \pm 154.24$ & 0.059 (NS) & 2.054 & $(\uparrow) 1.86$ \\
\hline Mineral $(\mathrm{kg})$ & $3.50 \pm 0.37$ & $3.53 \pm 0.33$ & 0.312 (NS) & 1.049 & $(\uparrow) 0.86$ \\
\hline Glycogen content (gm) & $440.00 \pm 41.01$ & $453.40 \pm 42.28$ & $0.002^{* *}$ & 3.896 & $(\uparrow) 3.04$ \\
\hline $\mathrm{Hb}(\mathrm{mg} / \mathrm{dl})$ & $13.47 \pm 0.86$ & $13.33 \pm 0.70$ & 0.099 (NS) & 1.769 & 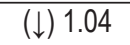 \\
\hline
\end{tabular}

Values are expressed as (mean $\pm \mathrm{SD}),{ }^{*}=\mathrm{p}<0.05,{ }^{* *}=\mathrm{p}<0.01,{ }^{* *}=\mathrm{p}<0.001$, NS $=$ not significant, FFM $=$ fat free mass, TBW $=$ total body water, ECW $=$ extracellular water, ICW $=$ intracellular water, $\mathrm{TBK}=$ total body potassium, $\mathrm{TBCa}=$ total body calcium, $\mathrm{Hb}=$ hemoglobin content.

Table 5. Comparison of physical fitness parameters between pre- and post-training groups of male cyclists

\begin{tabular}{|c|c|c|c|c|c|}
\hline Parameters & Before intervention $(n=15)$ & After intervention $(n=15)$ & Level of sig. & t value & \% change \\
\hline RBS & $1.23 \pm 0.09$ & $1.36 \pm 0.10$ & $0.000^{* * *}$ & 4.666 & $(\uparrow) 10.57$ \\
\hline HGS-R (kg) & $43.00 \pm 5.07$ & $45.40 \pm 5.99$ & $0.004^{* *}$ & 3.485 & $(\uparrow) 5.58$ \\
\hline HGS-L (kg) & $41.07 \pm 4.62$ & $44.53 \pm 4.75$ & $0.002^{* *}$ & 3.879 & $(\uparrow) 8.42$ \\
\hline Flexibility (cm) & $25.87 \pm 3.23$ & $27.27 \pm 3.79$ & $0.012^{*}$ & 2.881 & $(\uparrow) 5.41$ \\
\hline $\mathrm{VO}_{2 \max }\left(\mathrm{ml} \cdot \mathrm{kg}^{-1} \cdot \mathrm{min}^{-1}\right)$ & $51.66 \pm 3.08$ & $54.04 \pm 2.42$ & $0.000^{* * *}$ & 10.840 & $(\uparrow) 4.61$ \\
\hline$R_{\text {absolute }}$ (watt) & $538.13 \pm 121.42$ & $583.53 \pm 119.41$ & $0.000^{* * *}$ & 5.846 & $(\uparrow) 8.44$ \\
\hline $\mathrm{R}_{\text {relative }}$ (watt $/ \mathrm{kg}$ ) & $9.29 \pm 2.14$ & $10.10 \pm 2.03$ & $0.000^{* * *}$ & 4.664 & $(\uparrow) 8.72$ \\
\hline Acceleration (sec) & $3.68 \pm 0.33$ & $3.93 \pm 0.32$ & $0.000^{* * *}$ & 5.265 & $(\uparrow) 6.79$ \\
\hline Explosive leg strength (cm) & $51.73 \pm 4.17$ & $55.33 \pm 4.62$ & $0.000^{* * *}$ & 8.290 & $(\uparrow) 6.96$ \\
\hline Agility (sec) & $14.66 \pm 0.47$ & $14.89 \pm 0.40$ & 0.009 ** & 3.028 & $(\uparrow) 1.57$ \\
\hline
\end{tabular}

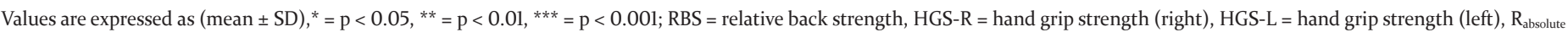
$=$ absolute peak anaerobic power output, $R_{\text {relative }}=$ relative peak anaerobic power output.

\section{Results}

Table 3 reveals the comparative assessment of general anthropometric characteristics of male cyclists. All the parameters were found to be slightly altered between before and after intervention; however, this alteration was statistically insignificant.

Table 4 depicts the comparison of body composition indices of male cyclists. Total body water (TBW) $(\mathrm{p}<0.001)$, TBW/ weight $(\mathrm{p}<0.01)$, intracellular water $(\mathrm{ICW})(\mathrm{p}<0.01)$ and glycogen $(p<0.01)$ were found to be significantly higher in after intervention group. On the other hand, extracellular water (ECW), ECW/weight, ECW/FFM and ECW/ICW were found to be lower in post-training group at $\mathrm{p}<0.01$ significance level except ECW/weight $(\mathrm{p}<0.05)$. Other parameters did not show any significant variation between the groups.

Table 5 shows the result of comparison between before and after intervention groups for physical fitness variables of male cyclists. Relative back strength, handgrip strength, flexibility,
$\mathrm{VO}_{2 \max }$, absolute peak anaerobic power $\left(\mathrm{R}_{\mathrm{absolute}}\right)$, relative peak anaerobic power $\left(R_{\text {relative }}\right)$ and vertical jump were found to be higher in post-training group at different statistically significant levels. In turn, $30 \mathrm{~m}$ flying start and 6 x $10 \mathrm{~m}$ shuttle run were found to be significantly lower in post-training groups.

\section{Discussion}

Track cycling events mostly last between 62 and 300 sec. Some of them require a higher activation of neuromuscular coordination along with higher recruitment of fast-twitch muscle fibers [4]. Track cyclists also need higher agility, leg explosive strength, $\mathrm{VO}_{2 \max }$ and anaerobic power output for better cycling performance [28]. In the case of the present study, the concurrent training protocol was intended to improve the hydration status [TBW $(\sim 1 \%)$ and ICW $(\sim 1 \%)$ ], glycogen content $(\sim 3 \%)$, muscular strength including back and grip strength ( 6-11\%), trunk flexibility $(\sim 5 \%)$, leg explosive strength ( 7\%), aerobic/ 
endurance capacity ( $5 \%)$, absolute and relative anaerobic power output $(\sim 9 \%)$, acceleration $(\sim 7 \%)$ and agility $(\sim 2 \%)$ of junior track cyclists.

White and Ford [29] outlined the importance of body fluids (hydration status) during cycling events and predicted its effect on energy output to constraints $\mathrm{VO}_{2 \max }$. A significant increase in TBW\% $(\mathrm{p}<0.001)$ and ICW\% $(\mathrm{p}<0.01)$ between before and after intervention groups of cyclists was found in the present study. The finding corroborates with the study of Mala et al. [30], where subsequent increases in ICW (56.4\% of TBW in females and $59.6 \%$ in males) were reported due to controlled sports training, which will correspond to an increase in active mass and musculature. Silva et al. [31] reported a positive correlation of TBW and ICW with upper body power and forearm maximal strength, which just validates the improved result of isokinetic strength of handgrip and back muscles in the cyclists under investigation.

Except the alterations in extracellular and intracellular water, a significant $(\mathrm{p}<0.001)$ increase in glycogen $(3 \%)$ was noted in the post-training period, which might be due to the improved rate of glycogen resynthesis and refilling by carbohydrate-rich diet (over 60\%) [32]. The present finding is in agreement with the study of Burgomaster et al. [33], where an increase in resting glycogen content was reported with a concomitant reduction in glycogen utilization during the high-intensity exercise. It was concluded that an increase in protein content of GLUT4 in a human skeletal muscle is a probable reason for significantly altered fluid balance and glycogen store [33]. Saltin and Karlsson [34] also showed that the rate of muscle glycogen utilization was exponentially and positively related to exercise intensity.

Improvements in RBS (10.6\%) and handgrip strength in both hands (5.6\% and $8.4 \%)$ in the present study were in agreement with the earlier findings of Isner-Horobeti et al. [4]. The rapid increase in muscular strength was attributed to muscular hypertrophy due to eccentric resistance training which may lead to the development in both type I and type II (particularly type Ila and type IIx) muscle fibers [4, 35, 36]. On the other hand, the improvement in agility (1.5\%) and acceleration (6.4\%) might indicate the effects of concurrent training on neuromuscular coordination [35]. Widrick et al. [36] also reported a similar observation after a plyometric session where improvements in leg press, vertical jump and $6 \times 5 \mathrm{~m}$ shuttle run were found. In turn, Neumann et al. [37] reported the potential power of muscles to be particularly dependent on fatigue-resistant slow-twitch fibers. As Kwon and Park [38] stated, eccentric muscle work recruits a larger area of the cortex, which is a complex work fully dependent on the neuromuscular adjusting [38]. Alteration in neuromuscular status through resistance training may result in either greater muscle fiber recruitment or an increase in the firing frequency of the motor units [39].

Long-term endurance power (aerobic metabolism prevails) is important as it potentiates muscular peak force throughout the cycling competition [37]. In the present study, a significant increase in $\mathrm{VO}_{2 \max }(4.6 \%)$ was found in the post-training group of cyclists, which is in line with the findings of other researchers $[28,40]$. An increase in the peripheral factor gradient, i.e., muscle capillary and mitochondrial density might be one of the factors responsible for improving $\mathrm{VO}_{2 \max }$ after an intensive training period [41]. However, Raastad et al. [42] depicted a negative role of a longer period of concurrent training on $\mathrm{VO}_{2 \max }$. In turn, Fagard et al. [42] and Fananapazir et al. [44] identified changes in left ventricular mass (LVM) along with mass-to-volume ratio and increased end-diastolic volume as the adaptive character- istics of competitive cyclists to meet the increased oxygen demand during a cycling event.

The highest power output $\left(\mathrm{W}_{\max }\right)$ was identified as one of the principle predictors of cycling performance [45]. In the current study, $\mathrm{R}_{\text {absolute }}$ and $\mathrm{R}_{\text {relative }}$ revealed the effectiveness of concurrent training $(\mathrm{p}<0.001)$ with a respective improvement by $8.4 \%$ and $8.7 \%$. It may result from a higher activity level of glycolytic enzymes in cyclists than in any other athletes, which made track cyclists more prone to adapt higher anaerobic power output [37]. A few other studies depict a similar improvement in anaerobic power output even at lactate threshold (LT) point in sedentary men [46] and in well-trained cyclists [28] In the present study, static and explosive muscle strength, anaerobic power output and endurance capacity improved in a similar trend and did not affect the hydration status and body weight. Therefore, it may prove that functional impairment caused by repeated bouts of eccentric and plyometric training did not take place in this particular concurrent training intervention.

The present study does not have any control data to compare with the rate of change taking place among the cyclists due to the concurrent study protocol. The study does not include various submaximal training intensities of the concurrent training modalities and that can ultimately limit the findings. The study is again limited to checking muscle damage indices but there are still queries whether repeated prolonged bouts of plyometric and eccentric exercise may actually have a protective effect on attenuating muscle damage or not.

\section{Conclusion}

The present 4-week intervention protocol of concurrent eccentric cycling and plyometric training at the pre-competitive phase was intended to improve the hydration status [TBW $(\sim 1 \%)$ and ICW $(\sim 1 \%)]$, glycogen content $(\sim 3 \%)$, muscular strength including back and grip strength ( 6-11\%), trunk flexibility $(\sim 5 \%)$, leg explosive strength $(\sim 7 \%)$, aerobic/endurance capacity $(\sim 5 \%)$, absolute and relative anaerobic power output $(\sim 9 \%)$, acceleration $(\sim 7 \%)$ and agility $(\sim 2 \%)$ of junior track cyclists in a synchronized responsive manner. The overall improvement may stem from increased muscular hypertrophy, peripheral factor gradient, glycolytic and oxidative enzyme capacity with proper neuromuscular coordination, which ultimately helps the cyclists to pedal faster with higher muscular power output even for longer time. The present findings could be useful to cyclists in formulating a systematic conditioning training programme as per physiological demands and in reducing the chances of overtraining and injury throughout the training session.

\section{References}

1. Majumdar P., Sivaprakasam S. (2014). Effect of training load on some hormonal, hematological and biochemical profile of male cyclists. Annals of Applied Sport Science 2(2), 01-12.

2. Ebert T.R., Martin D.T., McDonald W., Victor J., Plummer J.,Withers R.T. (2005). Power output during women's World Cup road cycle racing. European Journal of Applied Physiology 95(5), 529-536. DOI: 10.1007/s00421-005-0039-y.

3. Haakonssen E., Barras M., Burke L.M., Jenkins D.G., Martin D.T. (2015). Body composition in female road and track endurance cyclists: Normative values and typical changes in female road and track endurance cyclists. European Journal of Sports Science 16(6), 645-653. DOI: 10.1080/17461391.2015.1084538. 
4. Isner-Horobeti M.E., Dufour S.P., Vautravers P., Geny B., Coudeyre E., Richard R. (2013). Eccentric exercise training: modalities, applications and perspectives. Sports Medicine 43, 483-512.

5. Kristoffersen M., Gundersen H., Leirdal S., Iversen V.V. (2014). Low cadence interval training at moderate intensity does not improve cycling performance in highly trained veteran cyclists. Frontiers in Physiology 31(5), 34.

6. Hody S., Croisier J.L., Bury T., Rogister B., Leprince P. (2019). Eccentric Muscle Contractions: Risks and Benefits. Frontiers in Physiology 10, 536. DOI: 10.3389/fphys.2019.00536.

7. Reeves N.D., Maganaris C.N., Longo S., Narici M.V. (2009). Differential adaptations to eccentric versus conventional resistance training in older humans. Experimental Physiology 94(7), 825-833.

8. Dufour S.P., Lampert E., Doutreleau S., Lonsdorfer-Wolf E., Billat V.L., Piquard F., Richard R. (2004). Eccentric cycle exercise: training application of specific circulatory adjustments. Medicine and Science in Sports and Exercise 36(11), 1900-6. DOI: 10.1249/01.mss.0000145441.80209.66.

9. Perrey S., Betik A., Candau R., Rouillon J.D., Hughson R.L. (2001). Comparison of oxygen uptake kinetics during concentric and eccentric cycle exercise. Journal of Applied Physiology 91(5), 2135-42. DOI: 10.1152/jappl.2001.91.5.2135.

10. Lechauve J.B., Perrault H., Aguilaniu B., Isner-Horobeti M.E., Martin V., Coudeyre E., Richard R. (2014). Breathing patterns during eccentric exercise. Respiratory Physiology and Neurobiology 202, 53-8.

11. Bonde-Petersen F., Knuttgen H.G., Henriksson J. (1972). Muscle metabolism during exercise with concentric and eccentric contractions. Journal of Applied Physiology 33(6), 792-5.

12. Moysi J.S., Garcia-Romero J.C., Alvero-Cruz J.R., VicenteRodriguez G., Ara I., Dorado C., Calbet J.A.L. (2005). Effects of eccentric exercise on cycling efficiency. Canadian Journal of Applied Physiology 30(3), 259-275. DOI:10.1139/ h05-119.

13. Vogt M., Hoppeler H. (2014). Eccentric exercise - mechanisms and effects when used as training regime or training adjunct. Journal of Applied Physiology 116(11), 1446-1454.

14. Paulsen G., Eidsheim H.Ø., Helland C., Seynnes O., Solberg P.A., Rønnestad B.R. (2019). Eccentric cycling does not improve cycling performance in amateur cyclists. PLoS ONE 14 (1), e0208452. DOI:10.1371/journal. pone.0208452.

15. Grerstner L. (2007). The effect of plyometric training on the performance of cyclists. Master degree thesis. Sports Science. Stellenbosch University.

16. Markovic G., Mikulic P. (2010). Neuro-musculoskeletal and performance adaptations to lower-extremity plyometric training. Sports Medicine 40(10), 859-895.

17. Chimera N.J., Swanik K.A., Swanik C.B., Straub S.J. (2004). Effects of plyometric training on muscle-activation strategies and performance in female athletes. Journal of Athletic Training 39(1), 24-31.

18. Potteiger J.A., Lockwood R.H., Haub M.D., Dolezal B.A., Almuzaini K.S., Schroeder J.M., Zebas C. (1999). Muscle power and fiber characteristics following 8 weeks of plyometric training. Journal of Strength and Conditioning Research 13(3), 275-9.

19. Pellegrino J., Ruby B.C., Dumke C.L. (2016). Effect of plyometrics on the energy cost of running and $\mathrm{MHC}$ and titin isoforms. Medicine and Science in Sports and Exercise 48(1), 49-56.
20. Clark B., Costa V.P., O’Brien B.J., Guglielmo L.G., Paton C.D. (2014). Effects of a seven day overload-period of highintensity training on performance and physiology of competitive cyclists. PLoS ONE 9(12), ell5308. DOI: 10.1371/ journal.pone.0115308.

21. Borg G. (1998). Borg's perceived exertion and pain scales. Illinois: Human Kinetics.

22. Hawes M.R., Martin A.D. (2001). Human body composition. In R. Eston, T. Reilly (eds), Kinanthropometric and exercise physiology laboratory manual: test, procedures and data. Volume 1: anthropometry (pp. 3-53). London: Routledge.

23. Debnath M., Roy M., Chatterjee S., Dey S.K. (2016). Body composition profile of elite Indian male and female archers: a comparative study. International Journal of Health, Physical Education and Computer Science in Sports 23, 19-25.

24. Sarkar S., Debnath M., Chatterjee S., Dey S.K. (2018). Assessment of nutritional status, body composition parameters and physiological profiles of young male taekwondo and wushu players. International Journal of Sports Science and Medicine 2(1), 1-7.

25. Krasilshchikov O. (2014). Fitness profile of Malaysian adolescent squash players. Movement, Heath and Exercise 3, 3947.

26. Davis B., Bull R., Roscoe J., Roscoe D. (2000). Physical Education and the study of sport. 4th ed. UK: London Harcourt Publishers Ltd.

27. Bozkaya G., Ozgu E., Karaca B. (2010). The association between estimated average glucose levels and fasting plasma glucose levels. Clinics 65(11), 1077-1080.

28. Rønnestad B.R., Hansen J., Hollan I., Ellefsen S. (2015). Strength training improves performance and pedaling characteristics in elite cyclists. Scandinavian Journal of Medicine Science and Sports 25, e89-e98.

29. White J.A., Ford M.A. (1983). The hydration and electrolyte maintenance properties of an experimental sports drink. British Journal of Sports Medicine 17, 51-58.

30. Malá L., Bunc V., Malý T., Zemanová L. (2008). Current body composition of top senior judokas. Česká Kinantropologie 12(3), 85-81.

31. Silva A.M., Fields D.A., Heymsfield S.B., Sardinha L.B. (2011). Relationship between changes in total-body water and fluid distribution with maximal forearm strength in elite judo athletes. Journal of Strength and Conditioning Research 25(9), 2488-2495.

32. Reilly T., Secher N., Snell P., Williams C. (1990). Physiology of sports. London: Routledge.

33. Burgomaster K.A., Cermak N.M., Phillips S.M. (2007). Divergent response of metabolite transport proteins in human skeletal muscle after sprint interval training and detraining. American Journal of Physiology-Regulatory, Integrative and Comparative Physiology 292(5), R1970-R1976.

34. Saltin B., Karlsson J. (1971). Muscle glycogen utilization during work of different intensities. In M.B. Pernow, B. Saltin (eds), Muscle Metabolism During Exercise, New York: Plenum.

35. Mueller M., Breil F.A., Vogt M., Steiner R., Lippuner K., Popp A., et al. (2009). Different responses to eccentric and concentric training in older men and women. European Journal of Applied Physiology 107(2), 45-53.

36. Widrick J.J., Stelzer J.E., Shoepe T.C., Garner D.P. (2002). Functional properties of human muscle fibers after shortterm resistance exercise training. American Journal of Phy- 
siology-Regulatory, Integrative and Comparative Physiology 283(2), R408-R416. DOI: 10.1152/ajpregu.00120.2002.

37. Neumann G., Shephard R.J., Astrand P.O. (1992). Endurance in sport. The Encyclopedia of Sports Medicine. Oxford: Blackwell Scientific Publications.

38. Kwon Y.H., Park J.W. (2011). Different cortical activation patterns during voluntary eccentric and concentric muscle contractions: an fMRI study. Neuro Rehabilitation 29(3), 253-259.

39. Docherty D., Sporer B. (2000). A proposed model for examining the interference phenomenon between concurrent aerobic and strength training. Sports Medicine 30(6), 38594.

40. Aagaard P., Andersen J.L., Bennekou M., Larsson B., Olesen J.L., Crameri R., et al. (2011). Effects of resistance training on endurance capacity and muscle fiber composition in young top-level cyclists. Scandinavian Journal of Medicine Science and Sports 21, e298-e307.

41. Henriksson J., Sundberg C.J. (2010). General effects of physical activity. In Professional Associations for Physical Activity (Sweden), Physical Activity in the Prevention and Treatment of Disease. Stockholm: Swedish National Institute of Public Health.
42. Raastad T., Paulsen G., Refsnes P.E., Rønnestad B.R., Wisnes A.R. (2010). Strength Training - In theory and practice. Oslo: Gyldendal Undervisning.

43. Fagard R., Aubert A., Lysens R., Staessen J., Vanhees L., Amery A. (1983). Noninvasive assessment of seasonal variations in cardiac structure and function in cyclists. Circulation 67, 896-901.

44. Fananapazir L., Ryan-Woolley B., Ward C., White J.A. (1982). Echocardiographic left ventricular dimensions in two groups of road race cyclists during a training season. British Journal of Sports Medicine 16, 113-114.

45. Hawley J.A., Noakes T.D. (1992). Peak power output predicts maximal oxygen uptake and performance time in trained cyclists. European Journal of Applied Physiology and Occupational Physiology 65, 79-83.

46. McCarthy J.P., Agre J.C., Graf B.K., Pozniak M.A., Vailas A.C. (1995). Compatibility of adaptive responses with combining strength and endurance training. Medicine and Science in Sports and Exercise 27, 429-436.

Submitted: June 10, 2019.

Accepted: Decembeer 3, 2019. 